\title{
CANVAS: a late onset ataxia due to biallelic intronic AAGGG expansions
}

\author{
Natalia Dominik ${ }^{1}\left[\right.$ [D $\cdot$ Valentina Galassi Deforie $^{1} \cdot$ Andrea Cortese $^{1,2} \cdot$ Henry Houlden ${ }^{1}$
}

Received: 6 May 2020 / Revised: 19 August 2020 / Accepted: 20 August 2020 / Published online: 10 September 2020 (c) The Author(s) 2020

\begin{abstract}
The ataxias are a group of disorders that manifest with balance, movement, speech and visual problems. They can arise due to dysfunction of the cerebellum, the vestibular system and/or the sensory neurons. Genetic defects are a common cause of chronic ataxia, particularly common are repeat expansions in this group of conditions. Co-occurrence of cerebellar ataxia with neuropathy and vestibular areflexia syndrome has been termed CANVAS. Although CANVAS is a rare syndrome, on discovery of biallelic expansions in the second intron of replication factor $\mathrm{C}$ subunit $1(R F C 1)$ gene, we and others have found the phenotype is broad and $R F C l$ expansions are a common cause of late-onset progressive ataxia.

We aim to provide a review and update on recent developments in CANVAS and populations, where the disorder has been reported. We have also optimised a protocol for $R F C 1$ expansion screening which is described herein and expanded phenotype after analysing late-onset ataxia patients from around the world.
\end{abstract}

Keywords Late-onset ataxia $\cdot$ CANVAS $\cdot R F C l \cdot$ Repeat expansion $\cdot$ Southern blot

\section{Phenotype}

Late-onset ataxia is a common neurological condition, where failure of systems controlling motor coordination occurs. This can lead to falls because of gait and stance ataxia and severe limitations in daily life. The disorder can be acquired, hereditary or non-hereditary; and up to $60 \%$ of familial and $19 \%$ of sporadic cases could have a genetic basis [1-3] and in most patients, it can present without an obvious familial background [4]. CANVAS is a common cause of late-onset progressive ataxia and the CANVAS patients suffer from ataxia, sensory neuronopathy or neuropathy as well as vestibular dysfunction [5]. Efforts have been made to piece together the syndromic clinical features of CANVAS with the genetic information to allow for more accurate clinical diagnosis. Recently, Cortese et al. reported the clinical features in the first 100 genetically confirmed

Natalia Dominik

n.dominik@ucl.ac.uk

$\triangle$ Henry Houlden

h.houlden@ucl.ac.uk

1 Department of Neuromuscular Disorders, UCL Institute of Neurology, Queen Square, London WC1N 3BG, UK

2 Department of Brain and Behavioural Sciences, University of Pavia, Pavia, Italy
RFCl CANVAS cases [6]. The mean age of onset appears to be just over 50 years. Progressive unsteadiness was the most common complaint at disease onset and universally present during disease progression. A sensory neuropathy was identified as a common feature in all cases carrying biallelic AAGGG $R F C 1$ expansions. There is often intrafamilial variability in age at onset and severity in clinical features but we have not seen extreme differences. The repeat sizing on Southern blot does not allow accurate expansion size comparison although as numbers of cases increase and our Southern blot method improves this may be possible in the future. Patients often reported symptoms including loss of feeling, neuropathic pain, 'pins and needles' (paraesthesia) and unpleasant sensation in response to touch (dysesthesia), pointing to a damage to peripheral nerves. Notably, in some patients the disease manifested as isolated sensory neuropathy. Cerebellar involvement was observed in two thirds of patients, showing nystagmus, dysmetric saccades and broken pursuits and leading, as the disease progresses, to dysarthria and dysphagia. A characteristic radiological pattern of cerebellar atrophy affecting the vermis and hemispheric crus I was identified and further confirmed on post-mortem brains [5]. Vestibular areflexia is also often present and probably its frequency is still underestimated. Patients may complain of oscillopsia and, when clinically tested, vestibulo-ocular reflex is often bilaterally impaired. Interestingly, over $60 \%$ 
Fig. 1 Overall symptoms of CANVAS. Symptoms during the manifestation of the disease in 100 biallelic $R F C 1$ expansion cases. Listed are the number of patients reporting specific symptoms and a combination of two or more symptoms (multiple symptoms) (Adapted from Cortese et al. 2020 [6])

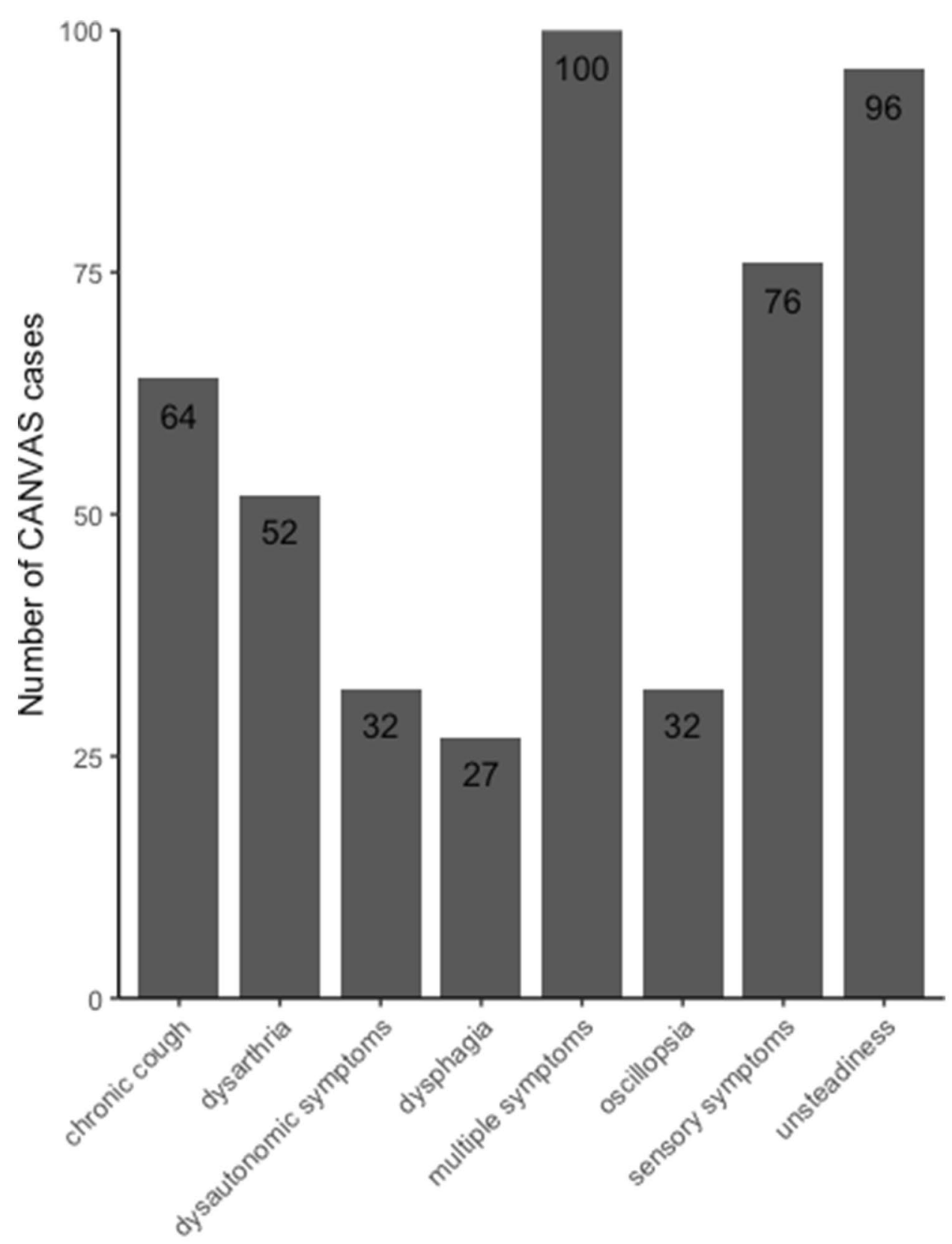

Overall Symptoms of CANVAS of CANVAS patients experience dry cough (Fig. 1) whose cause remains unexplained. The cough is reported up to 30 years before neurological onset $[6,7]$, and it is hypothesised to be arising either as hypersensitivity syndrome due to a peripheral mechanism, where dysfunction of $\mathrm{C}$ fibres at level of upper way or oesophagus occurs; or due to cerebellar circuitry impairment [7]. Nerve conduction studies show non-length dependant sensory neuropathy in all the tested patients. Motor nerve conduction is preserved [8]. Visualisation of symptoms of 100 genetically confirmed CANVAS cases can be seen in Fig. 1 [6].
Moreover, Szmulewicz [9] and Cortese [6] both describe tests and assessments used for clinical diagnosis of patients. Briefly, nerve conduction studies are employed to check for sensory nerve involvement. Vestibular impairment should be tested by either of the following: bilaterally abnormal video head impulse test, bilaterally reduced caloric response or reduced vestibulo-ocular reflex gain tested using a rotatory chair. And finally, a range of tests should be employed in autonomic assessment, where parasympathetic and sympathetic functions should be checked. Abnormal blood pressure responses may be observed 
during change in posture and handgrip in sympathetic assessments. Parasympathetic function may be impaired which could be observed in heart rate variation during deep breathing or standing. Other autonomic nervous system dysfunctions may be present and can include affected micturition and defecation.

CANVAS shares common clinical features with other ataxias such as Friedreich Ataxia (FA) and Spinocerebellar ataxias (SCAs) and with Multiple System Atrophy (MSA) (Table 1). Therefore, clinical diagnosis of CANVAS may be difficult and genetic investigations should follow.

\section{Repeat expansions in RFC1}

CANVAS phenotype is especially complex, as is its underlying genetic cause. A healthy individual carries a nucleotide sequence of AAAAG in their second intronic region in the $R F C l$ gene (hg19 chr4:39,350,045-39,350,103). The pentanucleotide is generally repeated 11 times; however, in affected individuals, the sequence is changed to AAGGG and the number of repeats becomes expanded from less than several hundred to more than 2000 times. The mutant repeat expansion is only pathogenic when present on both alleles. The disease can be either sporadic or occur in siblings. Notably, few families with cousins affected, suggesting a pseudodominant inheritance, were also reported; those individuals were biallelic for expanded AAGGG with one of the alleles coming from another branch of the family. The pathogenic AAGGG allele are fully penetrant, while so far, carriers of one AAGGG expanded allele are all unaffected [8]. Furthermore, biallelic (AAGGG) exp appears to be CANVAS specific: no mutant configurations were found in two separate cohorts of patients, in a cohort of 336 multiple system atrophy mainly Caucasian patients from various brain banks and 102 Chinese Han MSA patients [10, 11].

Expansions of non-pathogenic repeat units including AAAAG, AAAGG, AAGAG and AGAGG were also observed [8, 12]. Thus far, the biallelic mutant AAGGG expansion is the only conformation shown to cause disease. Indeed, Cortese reported healthy individuals with conformations such as (AAAAG) $)_{\exp } /(\mathrm{AAGGG})_{\exp }$, (AAAGG) $)_{\exp } /$ $(\mathrm{AAGGG})_{\exp }$ and $(\mathrm{AAAAG})_{\exp } /(\mathrm{AAAGG})_{\exp }$.
Table 1 Comparison of disorders with similar clinical manifestations to CANVAS

\begin{tabular}{|c|c|c|c|c|}
\hline Disease & CANVAS & Friedreich ataxia & $\begin{array}{l}\text { Spino-cerebellar } \\
\text { ataxia }\end{array}$ & Multi system atrophy \\
\hline Gene & RFC1 & FXN & $\begin{array}{l}\text { ATXN1-2-3, } \\
\text { CACNA1, several } \\
\text { others }\end{array}$ & $\begin{array}{l}\text { No definite gene } \\
\text { identified }\end{array}$ \\
\hline $\begin{array}{l}\text { Cerebellar } \\
\text { ataxia }\end{array}$ & Frequent & Yes & Yes & Yes (MSA-C) \\
\hline Neuropathy & $\begin{array}{l}\text { Sensory neuropathy } \\
\text { always present }\end{array}$ & $\begin{array}{l}\text { Frequent sensory } \\
\text { or sensory-motor } \\
\text { neuropathy }\end{array}$ & $\begin{array}{l}\text { Possible sensory or } \\
\text { sensory-motor neu- } \\
\text { ropathy depending } \\
\text { on subtype }\end{array}$ & Usually absent \\
\hline $\begin{array}{r}\text { Vestibular } \\
\text { areflexia }\end{array}$ & Frequent & Possible & Possible (SCA2) & Usually absent \\
\hline $\begin{array}{l}\text { Dysautono- } \\
\text { mia }\end{array}$ & Mild & Usually absent & Usually absent & Severe \\
\hline Onset & Usually late onset & $\begin{array}{l}\text { Usually early onset, } \\
\text { but late onset pos- } \\
\text { sible }\end{array}$ & $\begin{array}{l}\text { Usually early onset, } \\
\text { but late onset pos- } \\
\text { sible }\end{array}$ & Usually late onset \\
\hline $\begin{array}{l}\text { Additional } \\
\text { neuro- } \\
\text { logical } \\
\text { features }\end{array}$ & Cough & $\begin{array}{l}\text { Optic atrophy, hear- } \\
\text { ing loss, pyramidal } \\
\text { tracts involvement }\end{array}$ & $\begin{array}{l}\text { Pyramidal tracts } \\
\text { involvement, } \\
\text { parkinsonism, cog- } \\
\text { nitive impairment, } \\
\text { visual impairment, } \\
\text { variably associ- } \\
\text { ated depending on } \\
\text { subtype }\end{array}$ & $\begin{array}{l}\text { Parkinsonism, rapid } \\
\text { progression, REM } \\
\text { behaviour disorder }\end{array}$ \\
\hline $\begin{array}{l}\text { Extra neu- } \\
\text { rological } \\
\text { involve- } \\
\text { ment }\end{array}$ & No & $\begin{array}{l}\text { Cardiomyopathy, } \\
\text { diabetes, scoliosis }\end{array}$ & No & No \\
\hline
\end{tabular}

CANVAS, FA, SCA and MSA patients share a number of complaints which may include ataxia, sensory neuropathy, dysarthria and dysphagia [5-9, 22-25] 


\section{Populations}

The first cohort originating from 11 families with a CANVAS diagnosis studied by Cortese et al. consisted of 29 individuals of whom 23 were affected and six unaffected [8]. Additional cohort of 150 sporadic cases with late onset ataxia were screened and $22 \%$ of them were found to have the expanded AAGGG present and if only the individuals with sensory neuronopathy and/or bilateral vestibular areflexia were considered, the percentage would have been higher. The patients were of European ancestry [8]. Another cohort studied by Cortese included 363 Caucasian individuals with late-onset ataxia of whom 105 patients were identified to carry the biallelic (AAGGG) $)_{\exp }$ [6].

In a bioinformatics-based approach to screening the repeat expansions, a cohort of 35 individuals with clinically diagnosed CANVAS was recruited. Of those, 30 were found to carry the mutant biallelic repeat expansion and most of the individuals were of European ancestry and a few were of different ethnic backgrounds [13].

There are currently not many studies on non-European cohorts. However, Akcimen et al. screened a cohort of Brazilian and Canadian patients with ataxia [12]. Out of total of 177 patients, they identified only one Brazilian family with two affected siblings that have the biallelic mutant expansion and one Canadian case. Interestingly, they report novel pentanucleotide sequences-AAGAG and AGAGG; however, the Repeat-primed polymerase chain reaction (RP-PCR) plot for AAGAG does not show a typical saw tooth pattern but they further explain that Sanger sequencing was needed for its identification.

A few CANVAS cases were identified in Japan [14-16], of which one was genetically confirmed by long read sequencing and it has the same haplotype around $R F C l$ as most European cases [16].

Fan and colleagues screened a cohort of late-onset ataxia patients found in the Chinese Han population [11]. They established that the frequency of heterozygous AAGGG repeat expansion alleles in their ataxia cohort was similar to their multiple system atrophy cohort: $2.75 \%$ and $2.45 \%$, respectively; however, no biallelic cases were found. $\mathrm{Wu}$ and colleagues described 26 CANVAS patients in New Zealand, all of them were of European ancestry with four patients also having New Zealand Maori and two patients having Polynesian ancestries [17].

The frequency of the (AAGGG) $)_{\exp }$ allele differs between populations worldwide. The majority of the reported CANVAS cases are European and indeed an ancestral haplotype has been identified and it is estimated to have emerged more than 25,000 years ago, likely in Europe [13]. In a cohort of European descent, the allelic

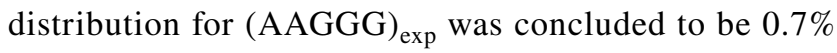
and conversely, the wild type, non-expanded AAAAG allele frequency equals $75.5 \%$ [8]. In a Canadian cohort of 163 control individuals, the frequency of expanded AAGGG was $4 \%$ and non-expanded AAAAG, $84.6 \%$ [12]. In 490 healthy Chinese Han individuals, the frequency of (AAGGG) $)_{\exp }$ was found to be $2.24 \%$ and for (AAAAG) ${ }_{11}$, $70.82 \%$ [11].

Based on allele frequency the estimated disease prevalence at birth ranges from 1:10,000 to 1:650 individuals [6]. Wu et al. estimated the disease prevalence in Auckland, New Zealand to be nearly 1:100,000 [17].

It appears that the AAGGG mutant expansion is a common cause of late onset-ataxia and it is underdiagnosed or misdiagnosed due to a range and variety of symptoms as well as relatively recent characterisation of the disorder $[5,18,19]$ and identification of the underlying genetic defect [8]. The incidence of (AAGGG) exp $_{\text {alleles is at its }}$ highest (92\%) in cases with typical CANVAS symptoms, this decreases; however, when only cerebellar ataxia with sensory neuropathy are characterised [6]. It is, therefore, of great importance that more individuals from different backgrounds are screened for possible $R F C 1$ pentanucleotide expansions to better characterise the disorder and aid clinical diagnosis as well as estimation of the global prevalence of (AAGGG) $)_{\text {exp. }}$

\section{Investigation methods for pentanucleotide expansions}

RP-PCR and flanking PCR are performed as previously described by Cortese et al. on genomic DNA [8]. Flanking PCR is employed to amplify the intronic $R F C l$ region and an affected individual will not show an amplified product on an agarose gel as opposed to non- affected individuals, where at least one PCR product corresponding to non-expanded AAAAG or intermediately expanded AAAAG, AAAGG or AAGGG can be amplified.

In patients, RP-PCR shows a typical saw-tooth decremental pattern (Fig. 2a) for AAGGG, but not AAAAG or AAAGG. Absence of amplified flanking PCR product together with saw-tooth decremental pattern on RP-PCR are highly predictive of biallelic $R F C 1$ expansion. It is important that flanking PCR and RP-PCR are used alongside and interpreted with caution. In rare instances, we observed no flanking PCR product in controls and negative RP-PCR for mutant expansions; however, positive RP-PCR for non-pathogenic expansions were found. Moreover, it is possible that flanking PCR will show no amplifiable product but positive RP-PCR for one allele with expanded AAGGG and one allele with expanded AAAGG for a non-affected individual.

Where cases likely positive for the biallelic AAGGG expansion in $R F C l$ are found, provided sufficient DNA is present, Southern blotting should be used for further confirmation of PCR results. Southern blotting is the current gold 

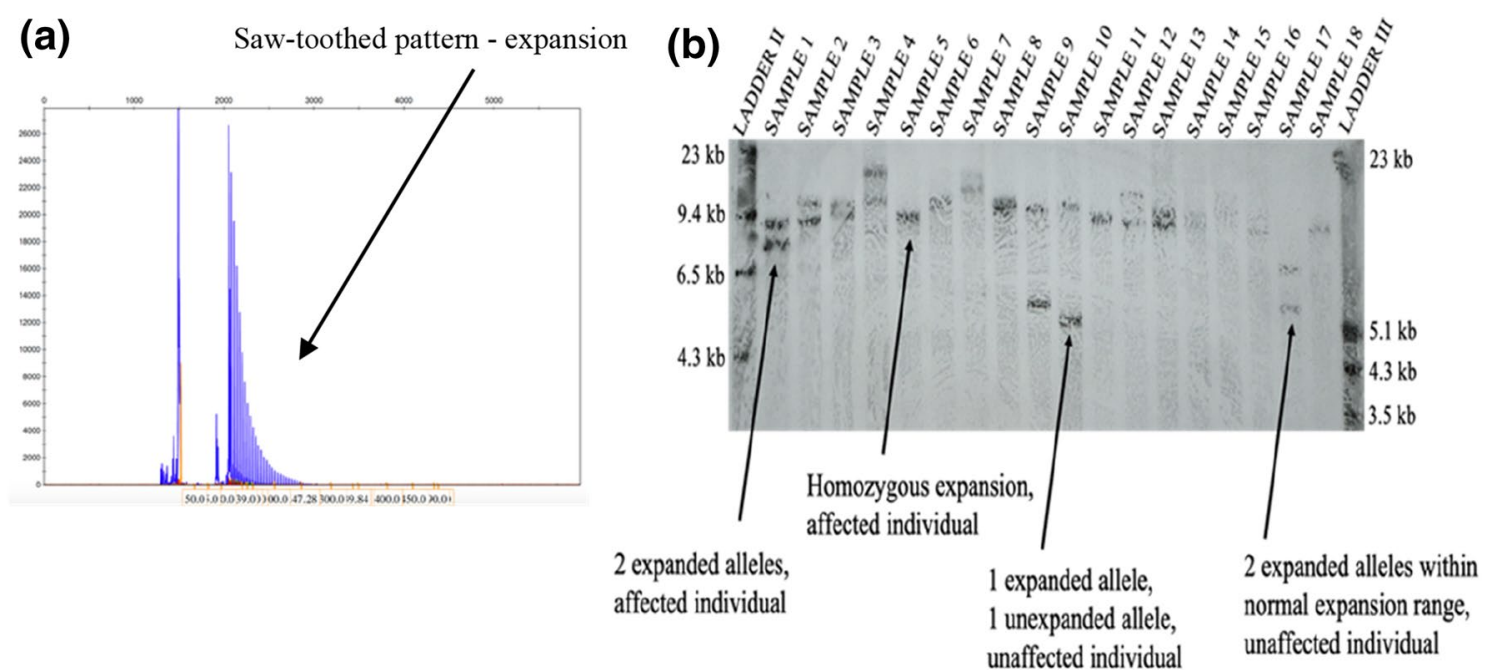

Fig. 2 RP-PCR and Southern blotting. a RP-PCR with primers targeting the AAGGG pentanucleotide repeated unit. An ABI 3730 DNA Analyser was used to separate the products, and these were visualised using GeneMapper. The presence of a 'sawtooth' pattern is characteristic of a possible affected individual $\mathbf{b}$ Patients are characterised by either one overlapping band or two bands within the region 7-15 kb. Carriers are identified with one band residing between 7 and $15 \mathrm{~kb}$ and the other at 5-6.5 kb, equivalent to the non-expanded AAGGG sequence or a small AAGGG expansion. Non-affected individuals exhibit two bands in regions between 5 and $6.5 \mathrm{~kb}$. Two ladders are needed for accurate measurements: DIG-labelled DNA Molecular Weight Marker II (Roche) (labelled as LADDER II) and DIG-labelled DNA Molecular Weight Marker III (Roche) (labelled as LADDER III). The left- and right-hand side of each panel documents the molecular weights represented by LADDER II and LADDER III, respectively. Overnight transfer with a $10 \mathrm{~min}$ exposure to the Fluorescent Detection Film
Fig. 3 Work flow diagram representing repeat expansion screening methodology. Flanking PCR and RP-PCR are used simultaneously on patient DNA to identify which are more likely to have two expanded alleles. If flanking PCR shows no amplifiable product and RPPCR shows typical saw-tooth pattern, southern blotting is carried out on additional patient DNA if available

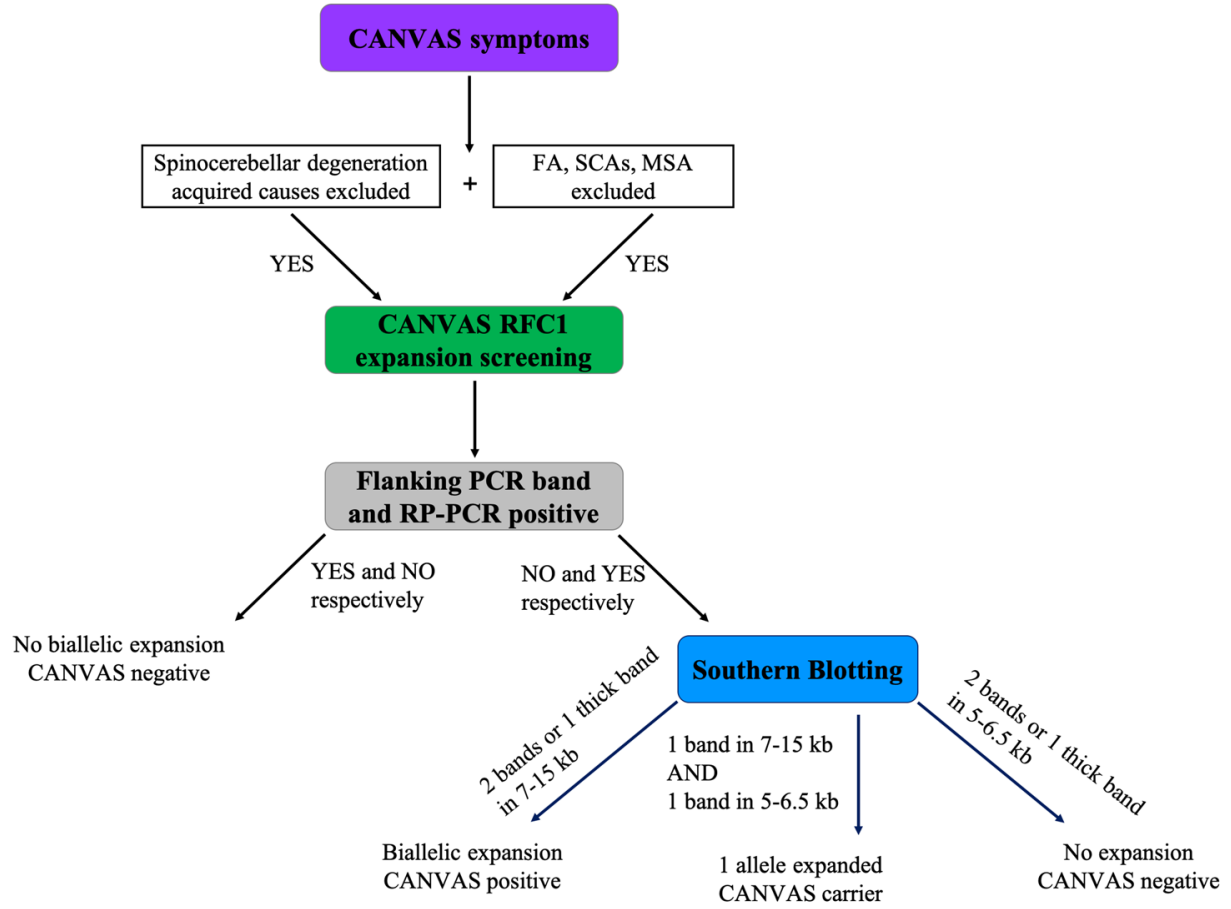

standard in measuring repeat expansions [20]. The screening process for pentanucleotide expansions is shown in Fig. 3.

We have optimised the Southern blot protocol for RFCl screening (Fig. 2b). Briefly, the changes from the original protocol, which produced good images in a lot of cases, include an overnight transfer of DNA to a positively charged nylon membrane as opposed to a transfer lasting $4 \mathrm{~h}$ which in a few cases resulted in an incomplete DNA 
transfer to the membrane (not shown). After transfer, prehybridisation was extended to $5 \mathrm{~h}$ from the original $3 \mathrm{~h}$ and the temperature was increased to $49{ }^{\circ} \mathrm{C}$ from $46{ }^{\circ} \mathrm{C}$. The increase of temperature was also implemented for the overnight hybridisation step. While five micrograms of good quality genomic DNA are still needed, bands are generally better visible and more blots are successful. Moreover, shorter exposure time for visualising the bands on fluorescent detection film can be used which leads to less background and higher quality image overall, we find that 10 min exposure produces clearest image. Biallelic expansions in affected individuals are seen as two bands between 7 and $15 \mathrm{~kb}$, or one thicker band if the expansions on both alleles are the same or similar size. Unaffected individuals who carry the mutation can either have one band in normal, wild type, range of $5 \mathrm{~kb}$ and one band in expanded range of 7-15 kb, or two expanded alleles-one in the non-pathogenic range of up to around $6.5 \mathrm{~kb}$ and one in the pathogenic range. Although Southern blotting is greatly important in repeat expansion screening, it has its limitations. Often, there might not be DNA available to perform the blotting as relatively large quantity $(5 \mu \mathrm{lor}$ more) of good quality (260/280 ratio of $1.8-2$ and 260/230 ratio of 2-2.2) DNA should be used. It is a time-consuming and labour intensive technique that requires a specific laboratory set-up and might fail at various stages; however, with our protocol optimisation, we observe good quality images.

Regardless of the limitations, we recommend that Southern blotting is used further to flanking PCR and RP-PCR in CANVAS screening.

Long-read sequencing can also be successfully employed to detect pathological repeat expansions as shown by Nakamura et al. [16]. Briefly, they obtained long reads from the patient and normal control DNA using PromethION sequencer (Oxford Nanopore Technologies, Oxford Science Park, UK). Then, they enriched the repeat regions with Cas9-mediated system and sequenced them using a MiniION nanopore sequencer. Human reference genome (hg38) was used to align the reads and tandem-genotypes v1.1.0 was used to conduce tandem repeat genotyping and multi-dataset prioritisation. Finally, $R F C 1$ repeat reads containing \pm 50 -bp flanking regions were aligned to generate a consensus repeat sequence.

\section{The disease-causing mechanism}

Currently, the mechanisms causing CANVAS are unknown, and this is, therefore, an ongoing area of research. The recent discovery of the recessive AAGGG repeat expansion in the $R F C l$ gene and has been identified as a frequent cause of this late-onset disease. This mutated expansion was compared to an expanded form of the reference sequence, AAAAG. Unlike the pathogenic $\mathrm{AAGGG}_{\text {exp }}$, individuals with either one or two copies of AAAAG $\mathrm{Axp}_{\text {exp }}$ do not exhibit symptoms.

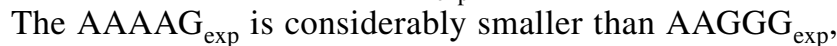
which indicates that both nucleotide change and expansion size have an impact on the pathogenic mechanism [8].

As the pathogenic repeat expansion is inherited in a recessive manner, it would be suspected that the mechanism of the disease would be a loss of function [21]. However, preliminary investigations mostly in non-affected tissues did not show a clear reduced expression of canonical $R F C l$ transcript or protein [8]. However, this does not exclude other effects that this repeat expansion may have, for example altering the organisation of chromatin or effect on other transcripts or isoforms or tissue specific consequences. These uncertainties about the underlying mechanism may be more complex than previously hypothesised and further research is needed to elucidate the pathogenic events in CANVAS patients.

\section{Conclusions}

Homozygous AAGGG expansions in RFCl gene appear to be a common cause of late onset ataxia. Efforts are being made to better characterise the phenotype of CANVAS disorder to aid clinical diagnosis. Most common complaints in patients with CANVAS include progressive unsteadiness at disease onset and during progression, sensory neuropathy and vestibular areflexia. In addition, cerebellar involvement leading to dysarthria and dysphagia may be observed. Patients may complain of oscillopsia and over $60 \%$ may experience unexplained dry cough. A variety of laboratory tests needs to be employed in parallel to find likely positive cases and those tests are cumbersome and relay on large quantities of genomic DNA. We improved Southern blotting which is a good technique for confirming the expansions; however, it has a variety of limitations and long read sequencing or other techniques could be sought out. The disease mechanisms are still elusive and further studies are needed to understand the pathogenicity of the mutant pentanucleotides.

Acknowledgements We would like to thank the participants and their families for their vital help with this work. We would like to thank the MSA Trust, The Medical Research Council, Ataxia UK, The Wellcome Trust, Fondazione CARIPLO and the Rosetrees Trust for funding support. We are also grateful to the NIHR UCLH Biomedical Research Centre for support. A.C. thanks Medical Research Council, (MR/ T001712/1), Fondazione CARIPLO (2019-1836) for Grant support.

Data availability Created in our laboratory. 


\section{Compliance with ethical standards}

Conflicts of interest The authors declare no conflicts of interest.

Ethical approval 07/N018 and REC Ref: 07/Q0512/26.

Consent to participate Yes in participating patients and families in research.

Open Access This article is licensed under a Creative Commons Attribution 4.0 International License, which permits use, sharing, adaptation, distribution and reproduction in any medium or format, as long as you give appropriate credit to the original author(s) and the source, provide a link to the Creative Commons licence, and indicate if changes were made. The images or other third party material in this article are included in the article's Creative Commons licence, unless indicated otherwise in a credit line to the material. If material is not included in the article's Creative Commons licence and your intended use is not permitted by statutory regulation or exceeds the permitted use, you will need to obtain permission directly from the copyright holder. To view a copy of this licence, visit http://creativecommons.org/licenses/by/4.0/.

\section{References}

1. Muzaimi MB, Thomas J, Palmer-Smith S, Rosser L, Harper PS, Wiles CM, Ravine D, Robertson NP (2004) Population based study of late onset cerebellar ataxia in south east Wales. J Neurol Neurosurg Psychiatry 75:1129-1134

2. Gebus O, Montaut S, Monga B, Wirth T, Cheraud C, Alves do Rego C, Zinchenko I, Carre G, Hamdaoui M, Hautecloque G, Nguyen-Them L, Lannes B, Chanson JB, Lagha-Boukbiza O, Fleury MC, Devys D, Nicolas G, Rudolf G, Bereau M, Mallaret M, Renaud M, Acquaviva C, Koenig M, Koob M, Kremer S, Namer IJ, Cazeneuve C, Echaniz-Laguna A, Tranchant C, Anheim M (2017) Deciphering the causes of sporadic late-onset cerebellar ataxias: a prospective study with implications for diagnostic work. J Neurol 264:1118-1126

3. Lieto M, Roca A, Santorelli FM, Fico T, de Michele G, Bellofatto M, Sacca F, de Michele G, Filla A (2019) Degenerative and acquired sporadic adult onset ataxia. Neurol Sci 40:1335-1342

4. Klockgether T (2010) Sporadic ataxia with adult onset: classification and diagnostic criteria. Lancet Neurol 9:94-104

5. Szmulewicz DJ, Waterston JA, Halmagyi GM, Mossman S, Chancellor AM, McLean CA, Storey E (2011) Sensory neuropathy as part of the cerebellar ataxia neuropathy vestibular areflexia syndrome. Neurology 76:1903-1910

6. Cortese A, Tozza S, Yau WY, Rossi S, Beecroft SJ, Jaunmuktane Z, Dyer Z, Ravenscroft G, Lamont PJ, Mossman S, Chancellor A, Maisonobe T, Pereon Y, Cauquil C, Colnaghi S, Mallucci G, Curro R, Tomaselli PJ, Thomas-Black G, Sullivan R, Efthymiou S, Rossor AM, Laura M, Pipis M, Horga A, Polke J, Kaski D, Horvath R, Chinnery PF, Marques W, Tassorelli C, Devigili G, Leonardis L, Wood NW, Bronstein A, Giunti P, Zuchner S, Stojkovic T, Laing N, Roxburgh RH, Houlden H, Reilly MM (2020) Cerebellar ataxia, neuropathy, vestibular areflexia syndrome due to $R F C 1$ repeat expansion. Brain 143:480-490

7. Infante J, Garcia A, Serrano-Cardenas KM, Gonzalez-Aguado R, Gazulla J, de Lucas EM, Berciano J (2018) Cerebellar ataxia, neuropathy, vestibular areflexia syndrome (CANVAS) with chronic cough and preserved muscle stretch reflexes: evidence for selective sparing of afferent Ia fibres. J Neurol 265:1454-1462
8. Cortese A, Simone R, Sullivan R, Vandrovcova J, Tariq H, Yau WY, Humphrey J, Jaunmuktane Z, Sivakumar P, Polke J, Ilyas M, Tribollet E, Tomaselli PJ, Devigili G, Callegari I, Versino M, Salpietro V, Efthymiou S, Kaski D, Wood NW, Andrade NS, Buglo E, Rebelo A, Rossor AM, Bronstein A, Fratta P, Marques WJ, Zuchner S, Reilly MM, Houlden H (2019) Biallelic expansion of an intronic repeat in $R F C 1$ is a common cause of late-onset ataxia. Nat Genet 51:649-658

9. Szmulewicz DJ, Roberts L, McLean CA, Macdougall HG, Halmagyi GM, Storey E (2016) Proposed diagnostic criteria for cerebellar ataxia with neuropathy and vestibular areflexia syndrome (CANVAS). Neurol Clin Pract 6:61-68

10. Sullivan R, Yau WY, Chelban V, Rossi S, O’Connor E, Wood NW, Cortese A, Houlden H (2020) RFC1 intronic repeat expansions absent in pathologically confirmed multiple systems atrophy. Mov Disord 35:1277-1279

11. Fan Y, Zhang S, Yang J, Mao CY, Yang ZH, Hu ZW, Wang YL, Liu YT, Liu H, Yuan YP, Shi CH, Xu YM (2020) No biallelic intronic AAGGG repeat expansion in $R F C 1$ was found in patients with late-onset ataxia and MSA. Parkinsonism Relat Disord $73: 1-2$

12. Akcimen F, Ross JP, Bourassa CV, Liao C, Rochefort D, Gama MTD, Dicaire MJ, Barsottini OG, Brais B, Pedroso JL, Dion PA, Rouleau GA (2019) Investigation of the $R F C 1$ repeat expansion in a Canadian and a Brazilian ataxia cohort: identification of novel conformations. Front Genet 10:1219

13. Rafehi H, Szmulewicz DJ, Bennett MF, Sobreira NLM, Pope K, Smith KR, Gillies G, Diakumis P, Dolzhenko E, Eberle MA, Barcina MG, Breen DP, Chancellor AM, Cremer PD, Delatycki MB, Fogel BL, Hackett A, Halmagyi GM, Kapetanovic S, Lang A, Mossman S, Mu W, Patrikios P, Perlman SL, Rosemergy I, Storey E, Watson SRD, Wilson MA, Zee DS, Valle D, Amor DJ, Bahlo M, Lockhart PJ (2019) Bioinformatics-based identification of expanded repeats: a non-reference intronic pentamer expansion in RFC1 causes CANVAS. Am J Hum Genet 105:151-165

14. Taki M, Nakamura T, Matsuura H, Hasegawa T, Sakaguchi $H$, Morita K, Ishii R, Mizuta I, Kasai T, Mizuno T, Hirano S (2018) Cerebellar ataxia with neuropathy and vestibular areflexia syndrome (CANVAS). Auris Nasus Larynx 45:866-870

15. Maruta K, Aoki M, Sonoda Y (2019) Cerebellar ataxia with neuropathy and vestibular areflexia syndrome (CANVAS): a case report. Rinsho Shinkeigaku 59:27-32

16. Nakamura H, Doi H, Mitsuhashi S, Miyatake S, Katoh K, Frith MC, Asano T, Kudo Y, Ikeda T, Kubota S, Kunii M, Kitazawa Y, Tada M, Okamoto M, Joki H, Takeuchi H, Matsumoto N, Tanaka $\mathrm{F}$ (2020) Long-read sequencing identifies the pathogenic nucleotide repeat expansion in $R F C 1$ in a Japanese case of CANVAS. J Hum Genet

17. Wu TY, Taylor JM, Kilfoyle DH, Smith AD, McGuinness BJ, Simpson MP, Walker EB, Bergin PS, Cleland JC, Hutchinson DO, Anderson NE, Snow BJ, Anderson TJ, Paermentier LA, Cutfield NJ, Chancellor AM, Mossman SS, Roxburgh RH (2014) Autonomic dysfunction is a major feature of cerebellar ataxia, neuropathy, vestibular areflexia 'CANVAS' syndrome. Brain 137:2649-2656

18. Szmulewicz DJ, Merchant SN, Halmagyi GM (2011) Cerebellar ataxia with neuropathy and bilateral vestibular areflexia syndrome: a histopathologic case report. Otol Neurotol 32:e63-e65

19. Szmulewicz DJ, Waterston JA, Macdougall HG, Mossman S, Chancellor AM, McLean CA, Merchant S, Patrikios P, Halmagyi GM, Storey E (2011) Cerebellar ataxia, neuropathy, vestibular areflexia syndrome (CANVAS): a review of the clinical features and video-oculographic diagnosis. Ann N Y Acad Sci 1233:139-147

20. Dolzhenko E, van Vugt J, Shaw RJ, Bekritsky MA, van Blitterswijk M, Narzisi G, Ajay SS, Rajan V, Lajoie BR, Johnson NH, 
Kingsbury Z, Humphray SJ, Schellevis RD, Brands WJ, Baker M, Rademakers R, Kooyman M, Tazelaar GHP, van Es MA, McLaughlin R, Sproviero W, Shatunov A, Jones A, Al Khleifat A, Pittman A, Morgan S, Hardiman O, Al-Chalabi A, Shaw C, Smith B, Neo EJ, Morrison K, Shaw PJ, Reeves C, Winterkorn L, Wexler NS, Group US-VCR, Housman DE, NG CW, Li AL, Taft RJ, van den Berg LH, Bentley DR, Veldink JH, Eberle MA (2017) Detection of long repeat expansions from PCR-free wholegenome sequence data. Genome Res 27:1895-1903

21. Shakkottai V, Paulson H (2019) Expanding the genetic basis of ataxia. Nat Genet 51:580-581
22. Delatycki MB, Corben LA (2012) Clinical features of Friedreich ataxia. J Child Neurol 27:1133-1137

23. Palma JA, Norcliffe-Kaufmann L, Kaufmann H (2018) Diagnosis of multiple system atrophy. Auton Neurosci 211:15-25

24. Kuzdas-Wood D, Irschick R, Theurl M, Malsch P, Mair N, Mantinger C, Wanschitz J, Klimaschewski L, Poewe W, Stefanova N, Wenning GK (2015) Involvement of peripheral nerves in the transgenic PLP-alpha-Syn model of multiple system atrophy: extending the phenotype. PLoS ONE 10:e136575

25. Sullivan R, Yau WY, O'Connor E, Houlden H (2019) Spinocerebellar ataxia: an update. J Neurol 266:533-544 